\title{
Turbulence and Diapycnal Mixing in Drake Passage
}

\author{
L. St. Laurent, * A. C. Naveira Garabato, ${ }^{+}$J. R. Ledwell, ${ }^{\#}$ A. M. Thurnherr, ${ }^{@}$ J. M. Toole, ${ }^{*}$ \\ AND A. J. WATSON\& \\ * Department of Physical Oceanography, Woods Hole Oceanographic Institution, Woods Hole, Massachusetts \\ ${ }^{+}$National Oceanography Centre, University of Southampton, Southampton, United Kingdom \\ \# Department of Applied Ocean Physics and Engineering, Woods Hole Oceanographic Institution, Woods Hole, Massachusetts \\ @ Division of Ocean and Climate Physics, Lamont-Doherty Earth Observatory, Palisades, New York \\ \& School of Environmental Sciences, University of East Anglia, Norwich, United Kingdom
}

(Manuscript received 2 February 2012, in final form 18 July 2012)

\begin{abstract}
Direct measurements of turbulence levels in the Drake Passage region of the Southern Ocean show a marked enhancement over the Phoenix Ridge. At this site, the Antarctic Circumpolar Current (ACC) is constricted in its flow between the southern tip of South America and the northern tip of the Antarctic Peninsula. Observed turbulent kinetic energy dissipation rates are enhanced in the regions corresponding to the ACC frontal zones where strong flow reaches the bottom. In these areas, turbulent dissipation levels reach $10^{-8} \mathrm{~W} \mathrm{~kg}^{-1}$ at abyssal and middepths. The mixing enhancement in the frontal regions is sufficient to elevate the diapycnal turbulent diffusivity acting in the deep water above the axis of the ridge to $1 \times 10^{-4} \mathrm{~m}^{2} \mathrm{~s}^{-1}$. This level is an order of magnitude larger than the mixing levels observed upstream in the ACC above smoother bathymetry. Outside of the frontal regions, dissipation rates are $O\left(10^{-10}\right) \mathrm{W} \mathrm{kg}^{-1}$, comparable to the background levels of turbulence found throughout most mid- and low-latitude regions of the global ocean.
\end{abstract}

\section{Introduction}

As evidence has accumulated in the last 30 years from finestructure and microstructure measurement programs (St. Laurent and Simmons 2006) in combination with tracer release experiments (Ledwell et al. 1993, 2000), a paradigm for ocean diapycnal mixing has developed in which mixing is weak through vast reaches of the ocean interior but greatly enhanced in the vicinity of rough bathymetry. Sites of particular interest are where ocean currents impinge on rough and/or abrupt bathymetric features to produce greatly intensified turbulence. Two diverse examples are abrupt, tall features like the Hawaiian Ridge (Rudnick et al. 2003; Klymak et al. 2006) and small-scale passages, like rift valleys (Thurnherr et al. 2005) and deep gaps connecting abyssal basins (Ferron et al. 1998). Midocean ridges, which comprise rough topography associated with fracture zones and transverse faults, as well as localized

Corresponding author address: Louis St. Laurent, Woods Hole Oceanographic Institution, 266 Woods Hole Rd., MS29, Woods Hole, MA 02543.

E-mail: 1stlaurent@whoi.edu peaks, also appear to support enhanced turbulence levels (Polzin et al. 1997; Ledwell et al. 2000). Typically located in the middle of oceanic basins away from enhanced boundary currents, the tides are often the largest source of energy at midocean ridge sites. Tidal flow incident on bathymetry leads to an internal wave response, principally at tidal frequencies (St. Laurent and Garrett 2002), that can radiate energy into the deep interior of the ocean. As internal waves radiate, they lose energy through a variety of instability and scattering mechanisms (Munk 1981; Polzin 2004; MacKinnon and Winters 2005); that energy in turn can support turbulence and mixing of the ocean's buoyancy field.

In contrast to most midocean regions of the subtropical basins, the Southern Ocean is a site of strong, deep-reaching geostrophic flow: the Antarctic Circumpolar Current (ACC). The ACC consists of a series of frontal zones where the flow is most enhanced-the Southern ACC Front (SACCF) to the south, the Polar Front $(\mathrm{PF})$ in the middle, and the Subantarctic Front (SAF) to the north. High rates of diapycnal mixing for the Southern Ocean as a whole have been suggested by box inverse studies of the circulation (Heywood et al. 2002; Lumpkin and Speer 2007; Zika et al. 2009). 
However, these estimates are indirect, being based mainly on mass balance derived from geostrophic flow estimates, and are subject to large uncertainty. Other studies have utilized finescale parameterizations for estimation of the mixing rates as part of larger-scale Southern Ocean (Sloyan 2005) and global ocean (Kunze et al. 2006) examinations. Both of these studies suggest enhanced mixing rates in various sectors of the ACC. In the case of Sloyan (2005), the enhanced mixing levels were collocated with the ACC frontal zones.

More focused studies have examined Drake Passage, where the ACC impinges on a series of topographic features as the meridional extent of the flow is compressed between South America and the Antarctic Peninsula. The Phoenix Ridge, along $66^{\circ} \mathrm{W}$, is the first in a series of ridges that the ACC encounters as it winds east through the Passage. The response of the flow to midocean ridges is of particular interest, as previous studies have suggested that this specific class of topography leads to both high-mode internal wave generation and bottom-enhanced flows in deep passages. In contrast to those previous midlatitude studies where tides were the dominant currents over the abyssal topography, the ACC incident on Phoenix Ridge varies on much longer time scales, favoring the production of internal lee waves (Nikurashin and Ferrari 2010). Combined with the short spatial scales of the bathymetric roughness along the ridge, these lee waves provide a mechanism for generating and then transporting internal wave energy at small-vertical scale into the deep interior where subsequent wave breaking can support turbulence and diapycnal mixing.

Estimates in the Drake Passage region include those described by Naveira Garabato et al. (2004), where finescale shear and strain levels were obtained during a hydrographic survey. Using the Polzin et al. (2002) parameterization based on the presumed cascade of shear and strain variance from large to small scales, they inferred large diffusivity levels, from $O\left(10^{-4}\right) \mathrm{m}^{2} \mathrm{~s}^{-1}$ to $O\left(10^{-3}\right) \mathrm{m}^{2} \mathrm{~s}^{-1}$, below approximately $1000-\mathrm{m}$ depth throughout the Drake Passage. However, other studies using the same parameterization as part of larger-scale Southern Ocean (Sloyan 2005) and global ocean (Kunze et al. 2006) examinations inferred more modest deep mixing levels, from $O\left(10^{-5}\right) \mathrm{m}^{2} \mathrm{~s}^{-1}$ to $O\left(10^{-4}\right) \mathrm{m}^{2} \mathrm{~s}^{-1}$, with local enhancements generally confined to depths below $1500 \mathrm{~m} .{ }^{1}$ In another Drake Passage study, Thompson

\footnotetext{
${ }^{1}$ The differing mixing levels are proportional to an assumed shear-to-strain ratio in the Polzin et al. (2002) parameterization. Sloyan (2005) used a value of 3, whereas Kunze et al. (2006) used 7, and Naveira Garabato et al. (2004) used 10.
}

et al. (2007) focused on the upper $1000 \mathrm{~m}$ of the water column and examined vertical overturns implied by inversions in temperature and density profile data from expendable instruments (XCTDs and XBTs). That work reported diffusivity levels implied by Thorpe Scales (Dillon 1982) reaching $10^{-3} \mathrm{~m}^{2} \mathrm{~s}^{-1}$ : values more than 100 times the diffusivity of the midlatitude thermocline.

Here we report the first direct measurements of turbulent kinetic energy dissipation rates, and the related diapycnal diffusivities, in Drake Passage. Our study is part of the Diapycnal and Isopycnal Mixing Experiment in the Southern Ocean (DIMES), a multifaceted experiment designed to examine diapycnal mixing and eddy stirring processes in the Southern Ocean (http:// dimes.ucsd.edu). The data reported here were collected during two surveys: the first on the U.S. vessel R/V Thomas G. Thompson, in March 2010, the second on the U.K. vessel RRS James Cook in December 2010. The earlier survey also supported an assessment of mixing levels upstream of Drake Passage, in the eastern Pacific sector of the Southern Ocean, where a tracer dispersion study of mixing had been underway for one year (Ledwell et al. 2011). Cruise reports for the DIMES expeditions can also be found online (at http://dimes. ucsd.edu).

\section{Observations}

Each survey included fine- and microstructure profiling, hydrographic measurements using CTD/Rosette casts, and ship- and lowered Acoustic Doppler Current Profiling (SADCP, LADCP) of the oceanic velocity structure. Measurements of velocity microstructure (reported here in terms of the dissipation rate of turbulent kinetic energy) were acquired at a total of 24 stations in Drake Passage: 10 along the Phoenix Ridge and 14 slightly upstream along the "ALBATROSS" hydrographic section (Naveira Garabato et al. 2007), as shown in Fig. 1. During the first survey, the following two profiling instrument systems were used: the High Resolution Profiler 2 (HRP2), built at Woods Hole Oceanographic Institution, and the Rockland VMP-6000 (RVMP), manufactured by Rockland Scientific International, Inc. During the December survey, two RVMP systems were used, one operated by $\mathrm{Na}$ tional Oceanographic Centre of the United Kingdom, and one by the Woods Hole Oceanographic Institution. HRP2 is similar to the original HRP (Schmitt et al. 1988). Further details on the RVMP instrument system are described online (at http://www.rocklandscientific. com). Both instruments measure centimeter-scale shear from which the dissipation rate of turbulent kinetic energy $\epsilon=(15 / 2) \nu \overline{(\partial u / \partial z)^{2}}$ may be estimated, where $\nu$ is the 


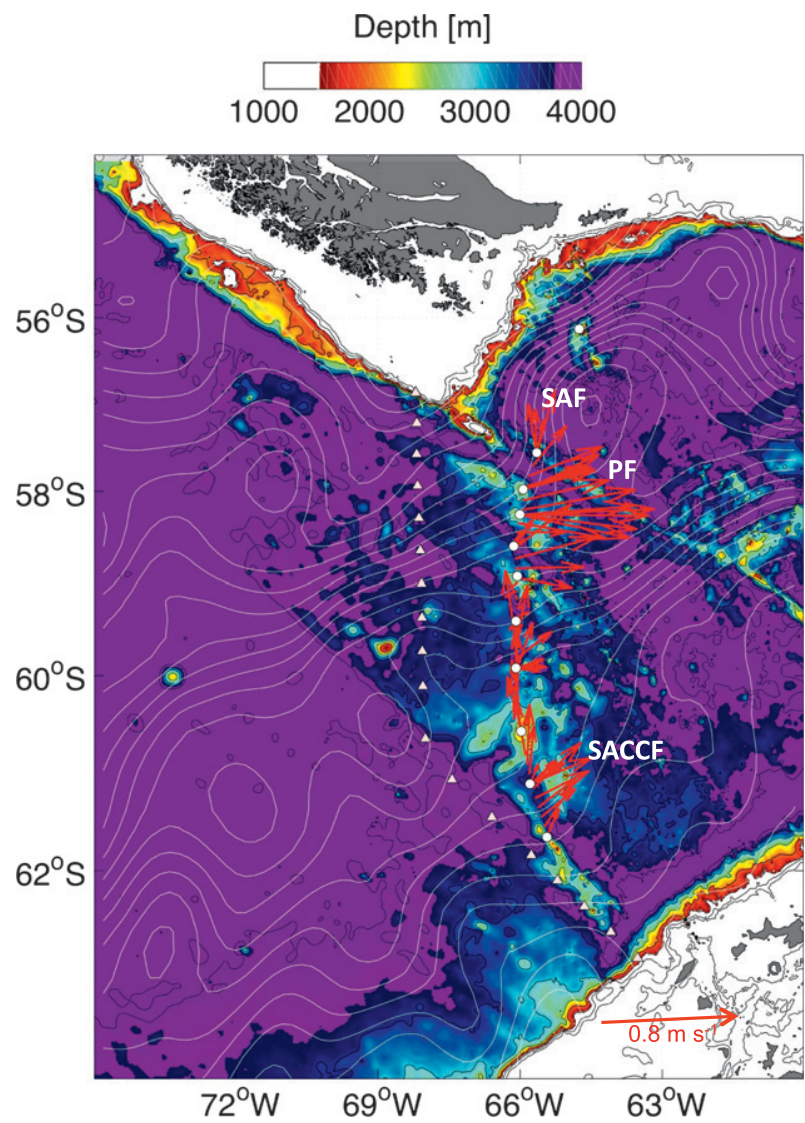

FIG. 1. Bathymetric chart (background color; from Smith and Sandwell, 1997) showing the Drake Passage survey stations of the ALBATROSS section (triangles) and the Phoenix Ridge (circles). The sea surface height field of the ACC is also shown at $5-\mathrm{cm}$ intervals, as inferred from satellite altimetry (AVISO) for 1 Mar 2010 [courtesy of Valery Kosneyrev (WHOI)]. Vectors for the observed flow along the Phoenix Ridge survey as measured by shipboard ADCP are depicted by red arrows. The SACCF, PF, and SAF zones are indicated.

molecular viscosity and isotropy is assumed. Estimates of the shear variance are done using spectral analysis in the manner described by Gregg (1999) over 1-m depth intervals of each microstructure-shear record. No spectral corrections are done to the shear spectra, as the inertial subrange and dissipative roll off were always well resolved. All profilers used dual-shear probes, and the dissipation rates reported are typically the mean of the independently estimated dissipation rates from each probe signal.

The sea surface height (SSH) field from Archiving, Validation, and Interpretation of Satellite Oceanographic data (AVISO) altimetry about the time of the Phoenix Ridge survey (Fig. 1) shows the predominantly zonal nature of the flow in the Passage. Surface layer currents, as measured along the Phoenix Ridge survey by SADCP, give a consistent picture, (Fig. 1), with the strongest currents focused in the three frontal regions. All of the frontal zones have deep reaching flows, as indicated by the LADCP measurements from each survey (Figs. 2 and 3 ) and those of previous expeditions (Naveira Garabato et al. 2004). The stronger flows are clearly associated with the frontal zones. Eddies are often present in Drake Passage, particularly up- and downstream of the Phoenix Ridge (Fig. 1), and do add a significant meridional component to the flow (Figs. 2 and 3 , right panels). In the frontal zones, the flow magnitude acting on the bottom topography is $U \approx$ $0.1 \mathrm{~m} \mathrm{~s}^{-1}$. Along the ALBATROSS section (Fig. 2), bottom currents in the frontal zones impinge on abyssal hill topography. Higher-amplitude variations in topography characterize the Phoenix Ridge (Fig. 3 ), where currents impinge on ridge crests as shallow as $2000 \mathrm{~m}$. LADCP sampling of the SAF zone above the Phoenix Ridge was not possible because of time constraints on the ship at the end of the survey.

At all stations in Drake Passage, a surface mixed layer was observed with large turbulent kinetic energy dissipation rate $(\epsilon)$ levels typical of surface-forced convective and shear-driven mixing (Figs. 4 and 5). The near-surface density structure was complex, with haline stratification dominating to the south in the SACCF and temperature stratification prevailing in the $\mathrm{PF}$ and SAF regions. Near-surface mixing will not be discussed further, as we will focus on the deep signals of mixing.

Microstructure sampling along the ALBATROSS section was broken into two segments, a region south of the SACCF about the southernmost extent of the Phoenix Ridge, and a region north of the SACCF through the PF and SAF regions (Fig. 4). While LADCP and CTD sampling was done in the SACCF region, microstructure sampling was not possible because of high seas and winds. In the PF zone, turbulent dissipation rates were enhanced in the bottom 500-m layer. The SAF was observed at the extreme northern limit of our survey, tightly bounded to the continental margin of South America. There, the single dissipation rate profile also shows enhanced near-bottom values. At heights exceeding 500-m above the bottom, there is no suggestion of enhanced turbulence levels, even in the frontal zones. At the level of the $\gamma_{n}=27.9 \mathrm{~kg} \mathrm{~m}^{-3}$ neutral density contour, a focus of the ongoing DIMES tracer study, turbulent dissipation rates are generally $\epsilon \sim 10^{-10} \mathrm{~W} \mathrm{~kg}^{-1}$, typical of the levels found just upstream of Drake Passage in the southeastern Pacific (Ledwell et al. 2011).

Observations along the Phoenix Ridge (Fig. 5), in contrast, document a more general enhancement of deep turbulent mixing in each of the SACCF, PF and SAF zones. In these frontal regions, observed dissipation 

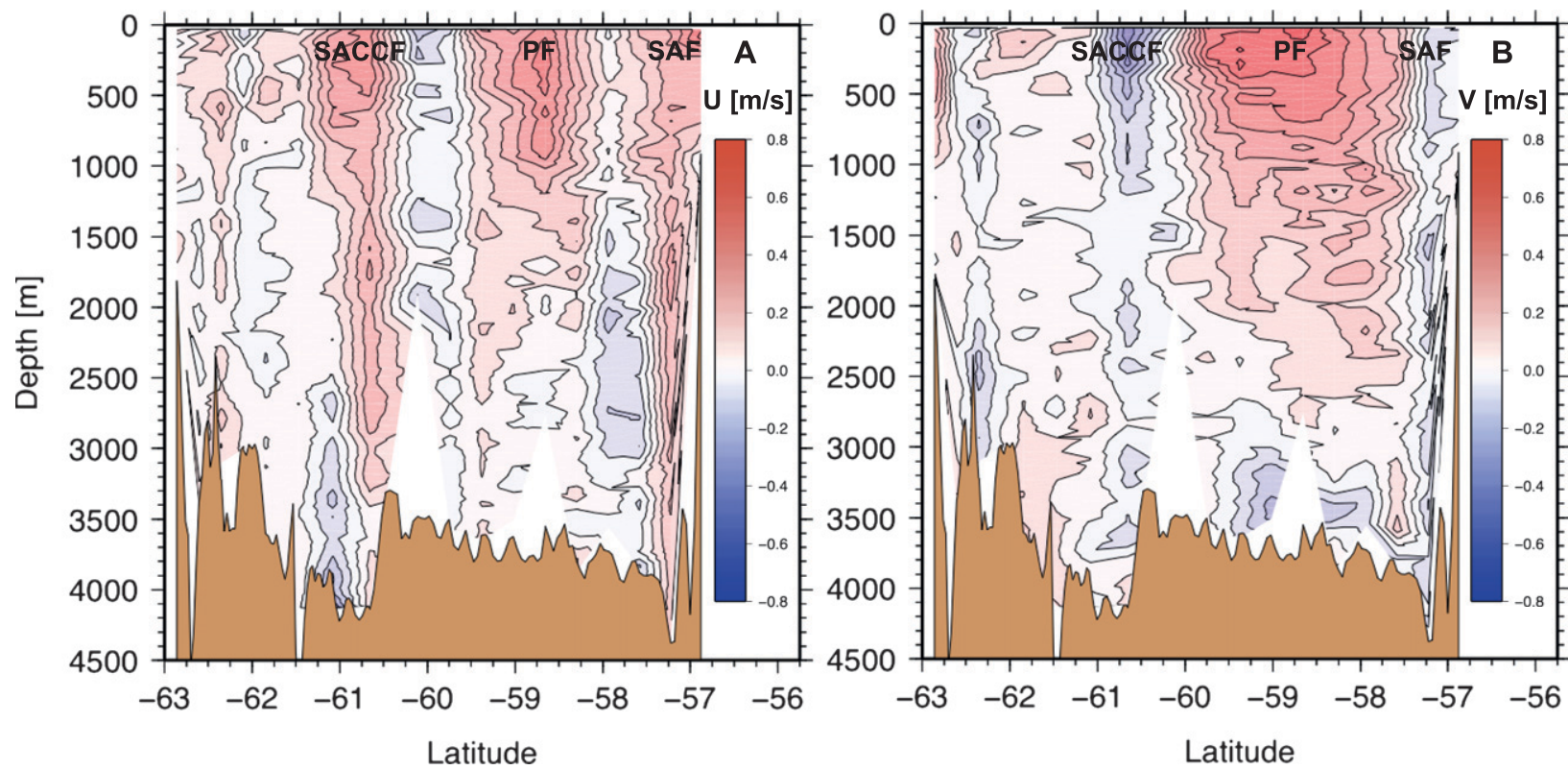

FIG. 2. Sections showing the LADCP measurements of velocity along the ALBATROSS section for (a) the zonal component of flow and (b) the meridional component. The frontal zones are denoted SACCF, PF, and SAF.

rate levels of $O\left(10^{-8}\right) \mathrm{W} \mathrm{kg}^{-1}$ extended up from the bottom to depths as shallow as $1000 \mathrm{~m}$. In general, enhanced levels of mixing extended further into the deep interior than observed on the ALBATROSS section, reaching the level of the $\gamma_{n}=27.9 \mathrm{~kg} \mathrm{~m}^{-3}$ neutral density contour. As was the case with the ALBATROSS section, the SAF was observed to be tightly bounded to the continental margin of S. America, with a single microstructure profile there indicating bottom enhancement of turbulence levels. Outside of the frontal regions, dissipation rates were typically $O\left(10^{-10}\right) \mathrm{W} \mathrm{kg}^{-1}$, with no enhancement near the bottom.
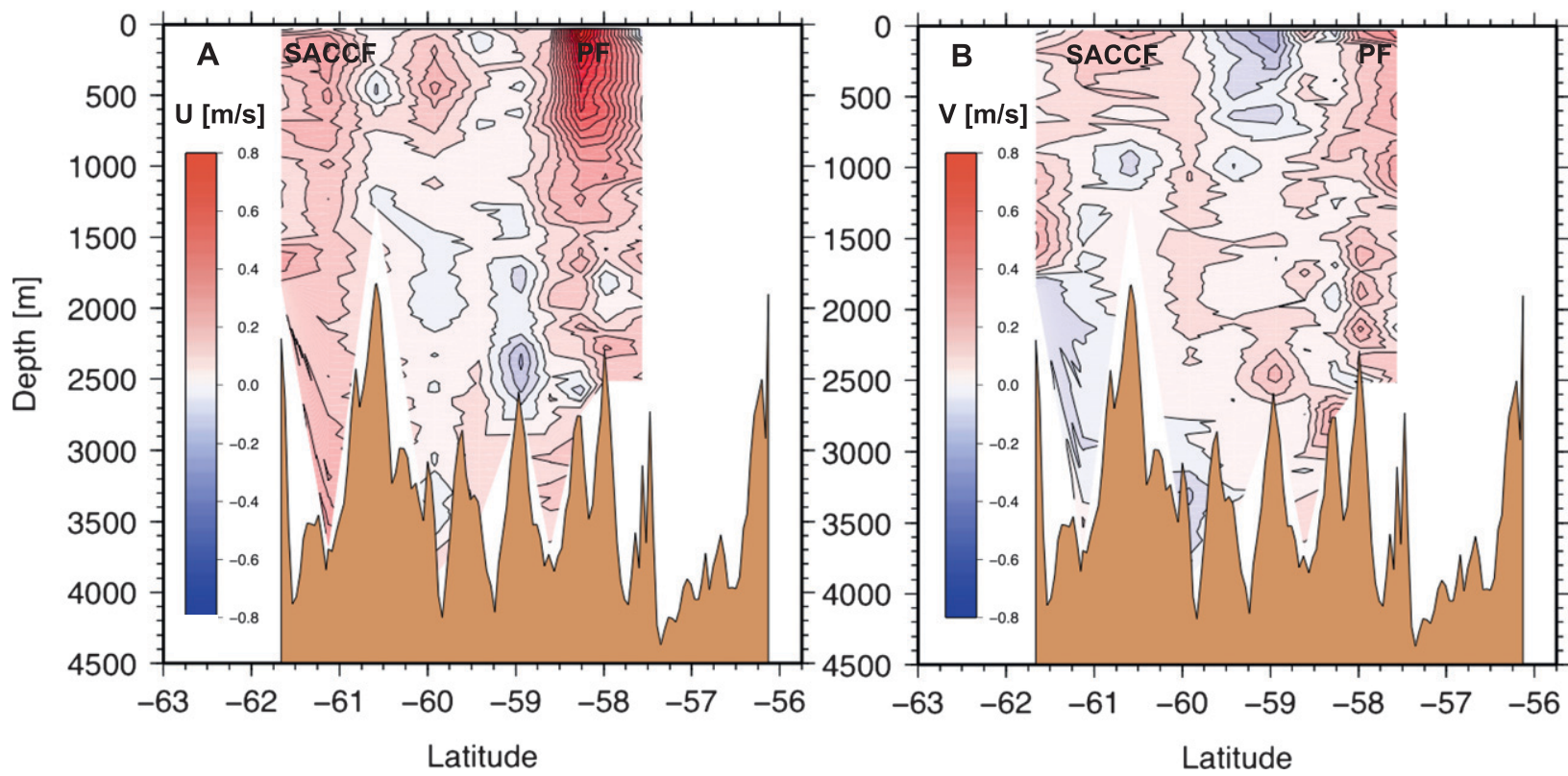

FIG. 3. Sections showing the LADCP measurements of velocity along the Phoenix Ridge section for (a) the zonal component of flow and (b) the meridional component. The frontal zones are denoted SACCF and PF. LADCP sampling was not done in the SAF region above the Phoenix Ridge. 


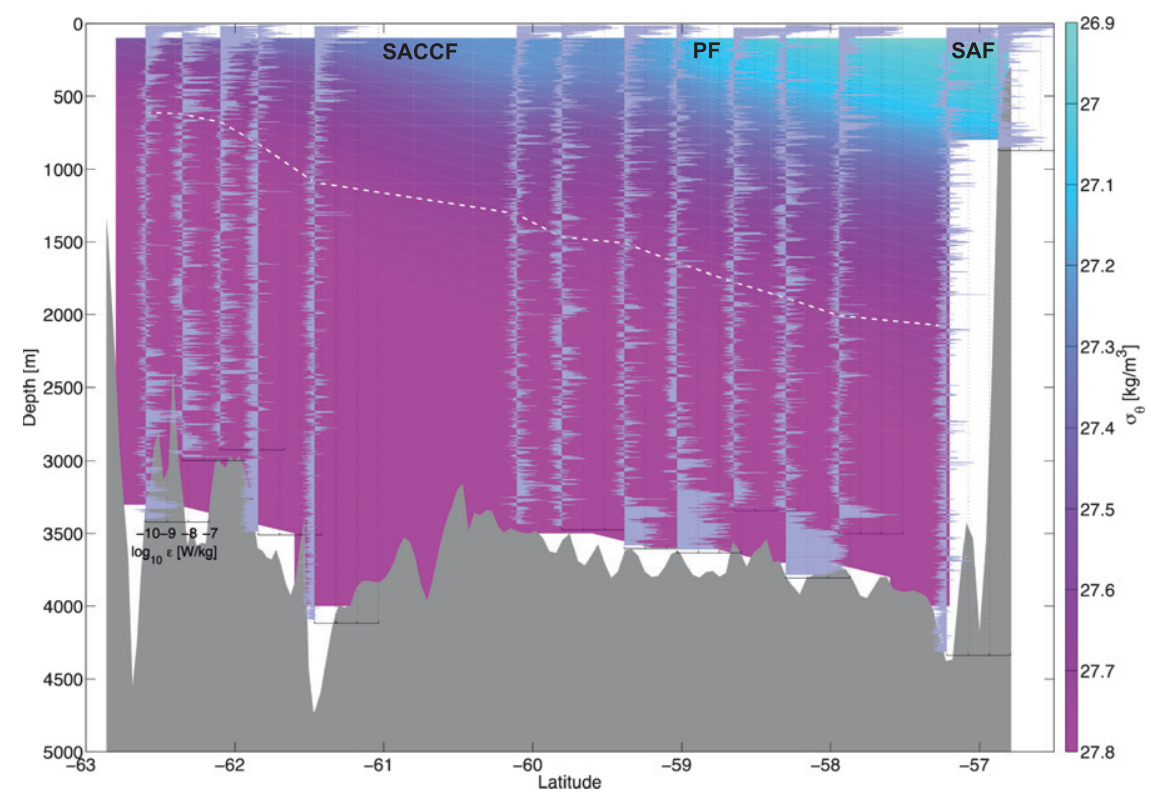

FIG. 4. Section of potential density anomaly relative to 0 dbar $\left(\sigma_{\theta}\right.$, color $)$, and turbulent energy dissipation rate ( $\varepsilon$; displayed on logarithmic scales from $10^{-10}$ to $10^{-7} \mathrm{~W} \mathrm{~kg}^{-1}$ ) for the ALBATROSS section. The dashed contour is the $\gamma_{n}=27.9 \mathrm{~kg} \mathrm{~m}^{-3}$ neutral density surface; the injection level of the DIMES tracer release. Bathymetry is shaded gray. The frontal zones are denoted SACCF, PF and SAF.

Average profiles of turbulent dissipation rate and diapycnal diffusivity were constructed for each section (Fig. 6), binned according to height above bottom (HAB). Diapycnal diffusivities, as formulated from the dissipation rate under the assumption that the turbulent kinetic energy budget is in statistical steady state for large ensembles, were calculated using the model of Osborn (1980): $k_{\rho}=\Gamma\langle\epsilon\rangle / N^{2}$. Here, $\Gamma$ is the mixing

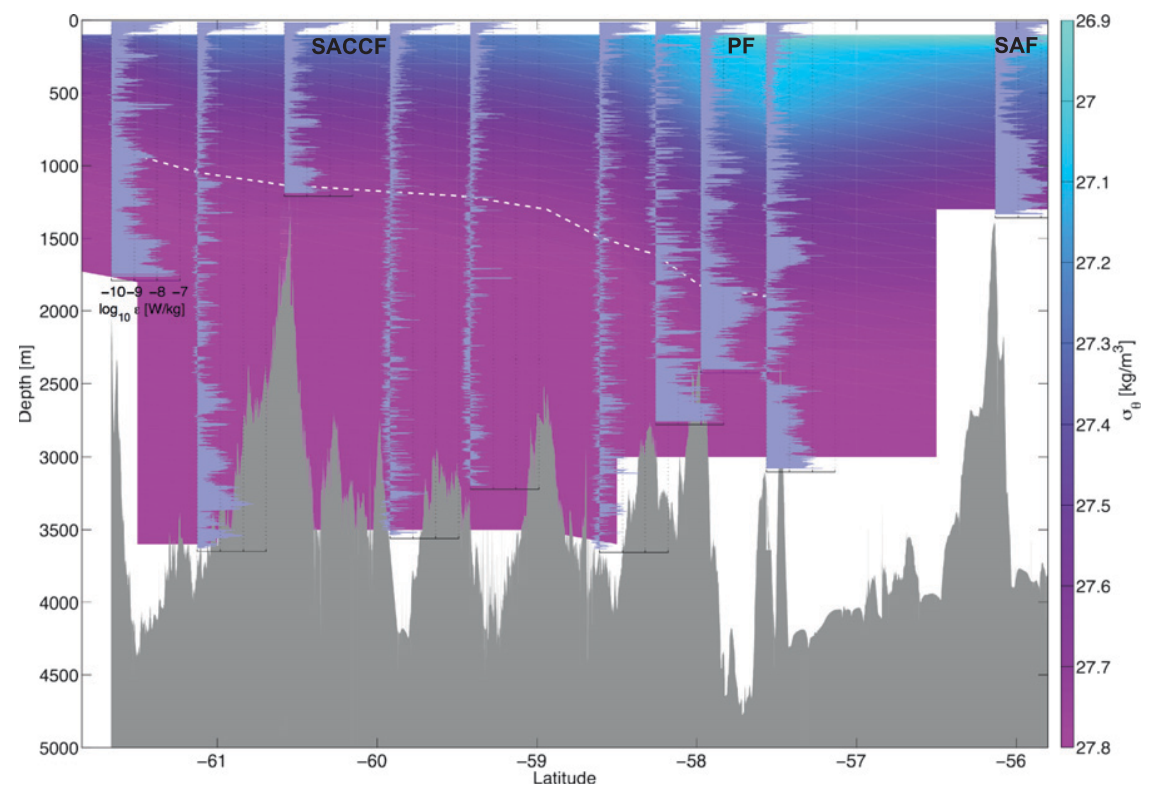

FIG. 5. Section of potential density anomaly relative to $0 \mathrm{dbar}\left(\sigma_{\theta}\right.$, color), and turbulent energy dissipation rate ( $\varepsilon$; displayed on logarithmic scales from $10^{-10}$ to $10^{-7} \mathrm{~W} \mathrm{~kg}^{-1}$ ) for the Phoenix Ridge. The dashed contour is the $\gamma_{n}=27.9 \mathrm{~kg} \mathrm{~m}^{-3}$ neutral density surface; the injection level of the DIMES tracer release. Bathymetry is shaded gray. The frontal zones are denoted SACCF, PF and SAF. 

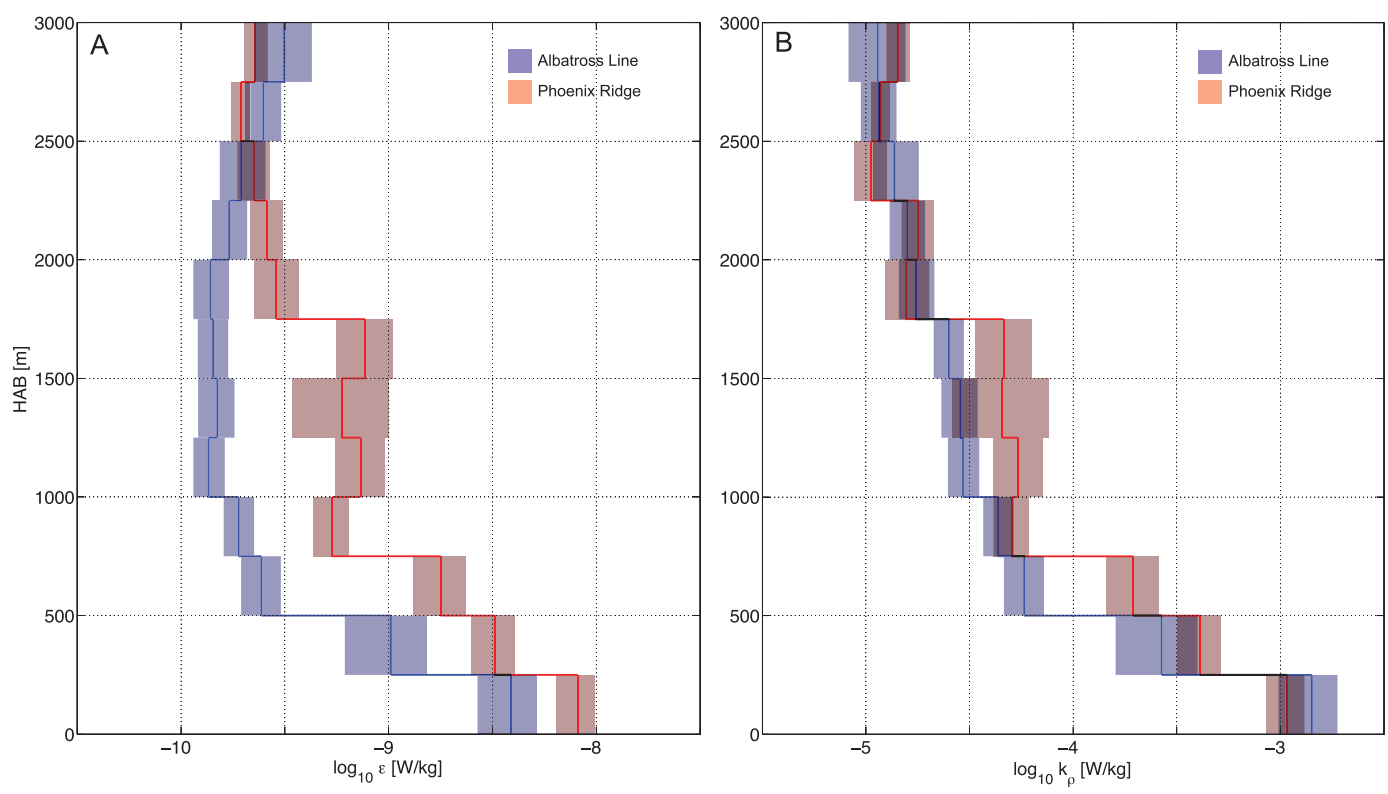

FIG. 6. Average HAB profiles of (a) turbulent kinetic energy dissipation and (b) diapycnal diffusivity as estimated from the microstructure data from both surveys. The ensembles of data from each survey were binned into 250-m HAB intervals, and mean (line segments) and 95\% confidence intervals (shaded bands) were estimated for each bin. Slightly darker shading indicates the overlap regions of the mean profiles in each panel. Data from depths shallower than $500 \mathrm{~m}$ were excluded from these average profiles. HAB estimates have an uncertainty of $\pm 25 \mathrm{~m}$, and most individual profiles terminated $(50 \pm 25) \mathrm{m}$ above the bottom.

efficiency parameter, which we take at the value of 0.2 , found to be appropriate for oceanic turbulence (St. Laurent and Schmitt 1999). The ensemble for dissipation values was taken over the combined set of all profiles sorted into 250-m HAB intervals. In the case of the ALBATROSS section data, both turbulence parameters have marked enhancements in the 500-m layer above the bottom. The Phoenix Ridge turbulence data have a similar enhancement in the bottom 500-m layer, but additionally show enhanced levels extending 1500-m above the local topography, through the depth horizon of the DIMES tracer release. It thus appears that the added amplitude of the ridge topography is necessary to elevate the turbulence intensity in the deep ocean interior.

Dissipation rate data were also characterized according to profiles measured both inside and outside of the three frontal zones (Fig. 7). Profiles from 13 frontal locations and 11 profiles outside of these locations were grouped together from both the ALBATROSS and Phoenix Ridge sections. The dissipation rate profile characterizing the mean of nonfrontal regions (Fig. 7a) is remarkably constant with $\mathrm{HAB}$, ranging from 1 to $3 \times$ $10^{-10} \mathrm{~W} \mathrm{~kg}^{-1}$. The ensemble mean profile characterizing the frontal zones (Fig. 7b), in contrast, shows a marked increase in dissipation rates closer to the topography. Figures $6 \mathrm{~b}$ and $7 \mathrm{~b}$ essentially show the same signal, as the same set of three profiles from the PF region of the Phoenix Ridge section dominate the mean ensembles.

The occurrence of enhanced dissipation rates only in frontal zones strongly suggests that the deep-reaching currents in these regions provide the energy that powers the turbulence. Kinetic energy of the flow was calculated from LADCP data as $K=0.5 \cdot \rho\left(U^{2}+V^{2}\right)$, where $\rho$ is the in situ density. For comparison to the measured turbulence levels, we examined the depth-integrated kinetic energy over the bottom-most $1000 \mathrm{~m}$ at each station, where flow energy should relate to the turbulence levels. Integrated dissipation levels were calculated as $D=\int_{-H}^{-H+1000 \mathrm{~m}} \rho \varepsilon d z$, and these are shown against integrated flow energy, $E=\int_{-H}^{-H+1000 \mathrm{~m}} K d z$, in Fig. 8. Both the ALBATROSS and Phoenix Ridge section data distribute along the trend of $D=C \cdot E^{P}$, where the least squares fit to the data cloud gives the power as $P=0.9 \pm 0.1$. The standard error was calculated using a bootstrap method treating each profile as a degree of freedom. Three cases where $D<$ $0.1 \mathrm{~mW} \mathrm{~m}^{-2}$ stand out in the ALBATROSS data, indicated in Fig. 8 as the opened circles. The two cases with $K \cong 5 \mathrm{~kJ} \mathrm{~m}^{-2}$ are from the stations near $61.5^{\circ}$ and $62^{\circ} \mathrm{S}$, and the case with $K \cong 17 \mathrm{~kJ} \mathrm{~m}^{-2}$ comes from the station near $57.2^{\circ} \mathrm{S}$. In all three cases, the bottom-most $1000-\mathrm{m}$ of data were in local topographic depressions, 

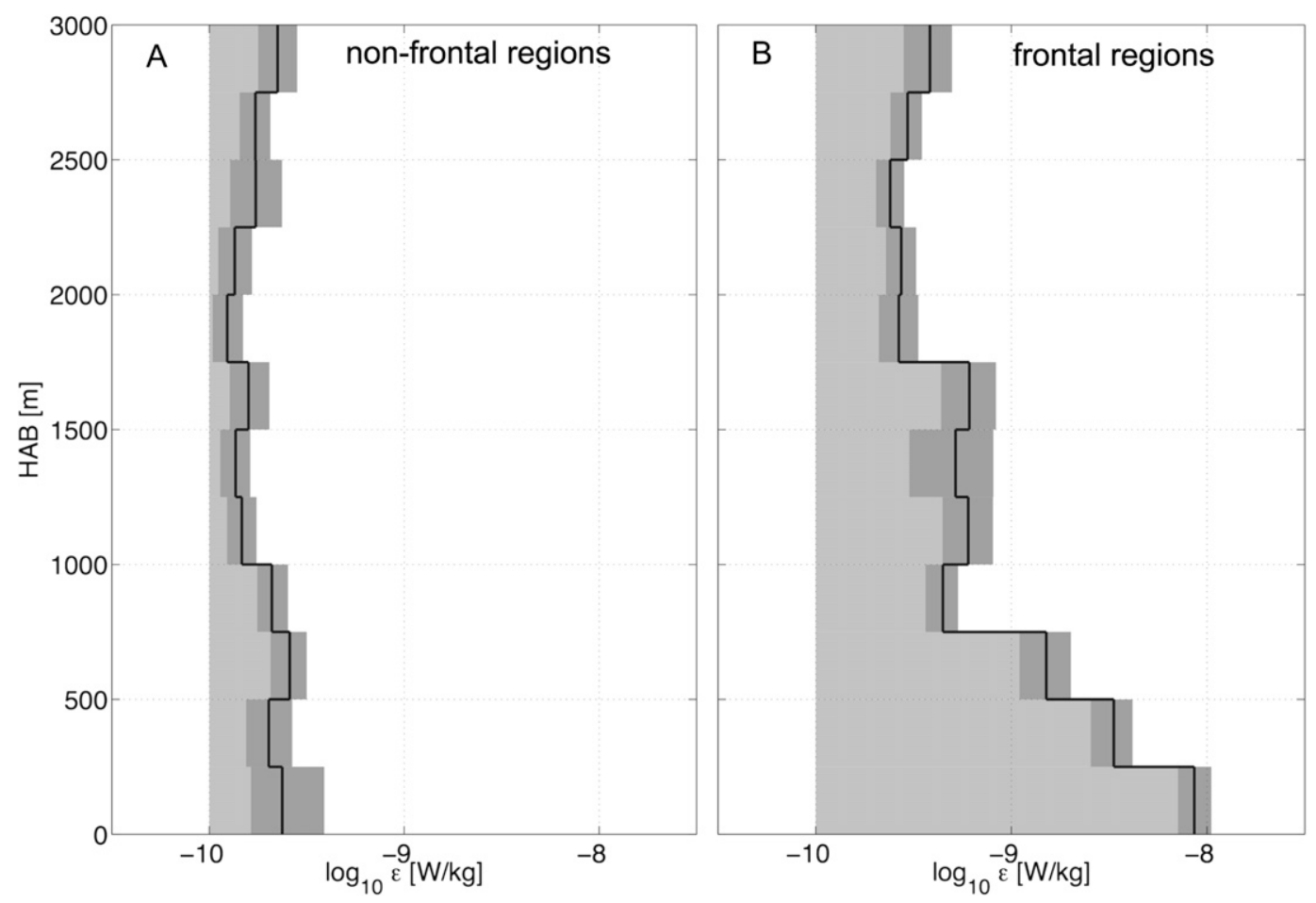

FIG. 7. Average $\mathrm{HAB}$ profiles of turbulent kinetic energy dissipation rates of (a) nonfrontal and (b) frontal regions as estimated from the microstructure data from both surveys. The ensemble means are as described in the caption of Fig. 6 . In each bin, the line denotes the mean, and the shading about the mean indicates the $95 \%$ confidence interval. Lighter gray shading fills the gap between the estimates and the oceanic background dissipation rate level of $1 \times 10^{-10} \mathrm{~W} \mathrm{~kg}^{-1}$.

suggesting these sites may be sheltered from flow in a way that inhibits the generation of turbulence. Considered independently from the ALBATROSS data, a least squares fit to the Phoenix Ridge data gives $D=C \cdot E^{(1 \pm 0.1)}$.

Past studies have implicated internal lee wave generation with the upward radiation and subsequent breaking of waves leading to small-scale turbulence (Naveira Garabato et al. 2004; Nikurashin and Ferrari 2010). Our best means of testing this hypothesis involves the analysis of vertical wavenumber spectra for finestructure energy. LADCP data are available for both surveys, allowing us to contrast the energy spectra at ALBATROSS and Phoenix Ridge sites (energy spectra measured by HRP2 (not shown), are consistent with the corresponding LADCP spectra collected along the Phoenix Ridge). Measured velocity records from the bottom 1000-m of each LADCP profile were extracted and used to construct rotary vertical wavenumber spectra (Fig. 9). The bulk of the finescale energy is found at vertical wavelengths between $\sim 1000$ and $300 \mathrm{~m}$. In this band, the energy in the clockwise-with-depth component is dominant. Interpreted as low-frequency internal waves, this implies a dominance of upward-propagating energy, consistent with lee waves being generated by the ACC impinging on topography (Nikurashin and Ferrari 2010). Finescale energy along the Phoenix Ridge is nearly five-times larger than the energy along the ALBATROSS section, consistent with the contrast in dissipation rate

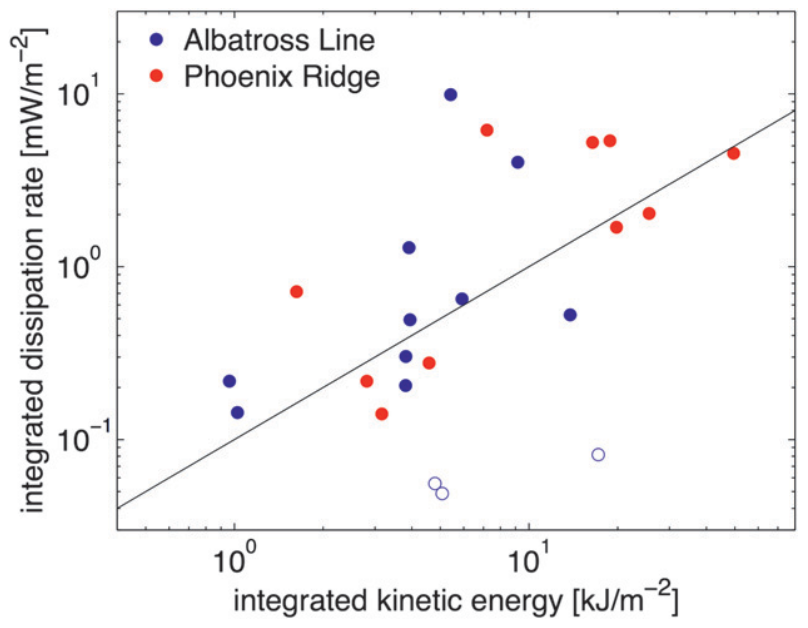

FIG. 8. Scatterplot of turbulent dissipation rate and flow kinetic energy, each depth-integrated over the bottommost $1000 \mathrm{~m}$, with data from the ALBATROSS section (blue) and Phoenix Ridge section (red). The line shows the trend for kinetic energy to the first power. Three cases with integrated dissipation less than $0.1 \mathrm{~mW} \mathrm{~m}^{-2}$, plotted with opened circles, are described in the text. 


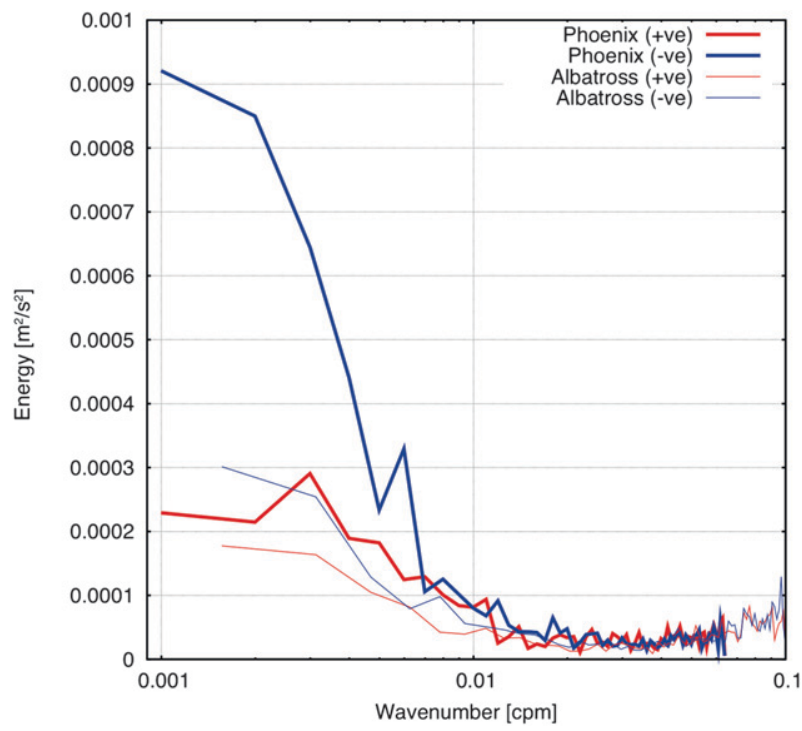

FIG. 9. Vertical wavenumber rotary energy spectra in variance preserving format. The clockwise (blue) and counterclockwise (red) rotary velocity components were derived from LADCP velocity data from the bottom $1000 \mathrm{~m}$ of each station. Phoenix Ridge measurements are shown in thicker lines. ALBATROSS section data are shown in thinner lines. Clockwise-with-depth variance corresponds to upward-propagating internal wave energy.

levels previously presented (Figs. 4 and 5). It thus appears that both the fine- and microscale energy (turbulence) are enhanced above the Phoenix Ridge relative to their values just slightly upstream along the abyssal hills of the ALBATROSS section.

The internal lee wave band is constrained by horizontal wavenumber according to $f / U<k<N / U$, where $f$ and $N$ are the inertial and buoyancy frequencies. Taking reference values of $f=1.2 \times 10^{-4} \mathrm{~s}^{-1}, N=10^{-3} \mathrm{~s}^{-1}$, and $U=10^{-1} \mathrm{~m} \mathrm{~s}^{-1}$, the lee wave band is defined by horizontal wavenumbers in the range of $500 \mathrm{~m}$ to $5 \mathrm{~km}$. It is a simple matter to use the dispersion relation, $m^{2}=$ $k^{2}\left(N^{2}-k^{2} U^{2}\right) /\left(k^{2} U^{2}-f^{2}\right)$, to infer the resulting vertical scales of the waves (Fig. 10). Vertical wavelengths of 300 to $1000 \mathrm{~m}$ define $80 \%$ of the total wave band for lee waves $\left(2.3 \times 10^{-4}<k<1.4 \times 10^{-3} \mathrm{cpm}\right)$, comparing well to the dominant energy-containing band noted in the measured spectra. Waves in this wavenumber range are characterized by intrinsic frequencies $(\omega=k \cdot U)$ from $1.17 \cdot f$ to $7 \cdot f$. Waves outside of this range have vertical group velocities that decay to zero (Nikurashin and Ferrari 2010), and thus do not contribute to the wavefield away from the bottom. Nikurashin and Ferrari (2010) found that the lee wave generation process also leads to inertial motions within a few hundred meters of the bottom. These inertial motions provide a background shear that enhances the potential for turbulence.

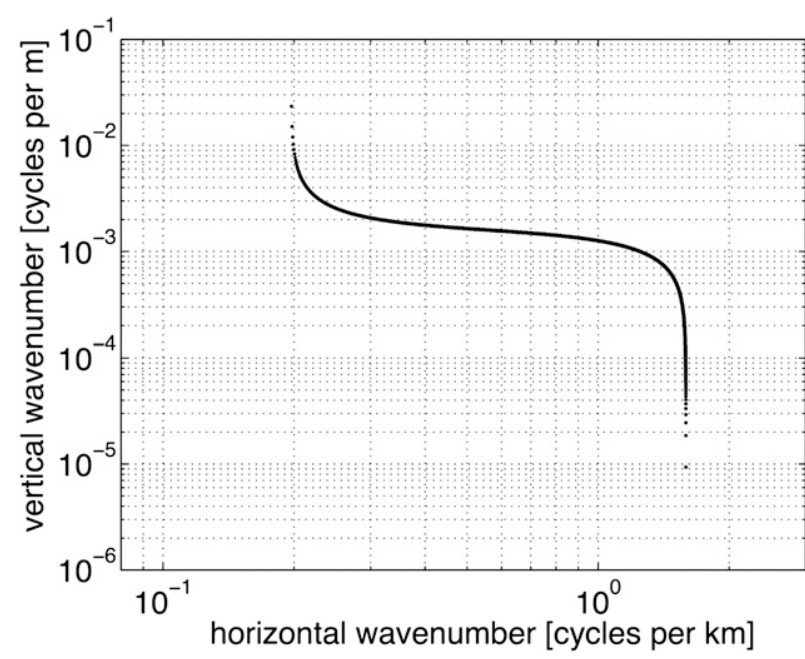

FIG. 10. The dispersion relation for lee waves, $m=k \sqrt{\left(N^{2}-k^{2} U^{2}\right) /\left(k^{2} U^{2}-f^{2}\right)}$, as computed for reference values of $f=1.2 \times 10^{-4} \mathrm{~s}^{-1}, N=10^{-3} \mathrm{~s}^{-1}$, and $U=10^{-1} \mathrm{~m} \mathrm{~s}^{-1}$. Most of the viable wave band has vertical wavelengths between 300 and $1000 \mathrm{~m}$. Outside of this range, the group speed decays to zero.

To what extent the turbulence levels we observe are promoted by inertial shear is yet to be determined, although it seems a likely possibility. Future studies that obtain both time series measurements and high-resolution along-flow section data at the ALBATROSS and Phoenix Ridge sites are recommended for a more rigorous test of the lee wave hypothesis. This would allow for an examination of data in an Eulerian frame, suitable for characterizing finescale energy levels in the inertial and radiating frequency bands.

\section{Discussion}

Our findings suggest that Drake Passage is a site of enhanced diapycnal turbulent mixing, where the deepreaching geostrophic flows associated with frontal zones of the ACC generate lee waves to feed the energy cascade to dissipative scales. Turbulence levels were larger along the Phoenix Ridge as compared to the ALBATROSS section located slightly upstream, where smaller-amplitude abyssal hills characterize the topography. Our measurements suggest that turbulence and mixing levels along the ALBATROSS line are moderately enhanced over midlatitude background levels in the deep and abyssal waters below 1500-m depth (Fig. 6). Our direct estimates are consistent with previous estimates by Kunze et al. (2006) who found $k_{\rho} \approx 10^{-4} \mathrm{~m}^{2} \mathrm{~s}^{-1}$ along the ALBATROSS line using the finescale parameterization for dissipation rate based on LADCP shear and strain on the data collected in the 1990s. The same data were examined by Naveira Garabato et al. (2004), who 
inferred turbulence levels an order-of-magnitude larger than the values of Kunze et al. (2006) and those reported here. The larger estimates of Naveira Garabato et al. (2004) appear to have been the result of noise in the integrated shear-variance in the higher-wavenumber range of the LADCP signal (Kunze et al. 2006).

Outside the frontal zones, we find relatively quiet turbulence levels at depth, and at all locations between the mixed layer transition zone and $\sim 1500 \mathrm{~m}$, in contrast to Naveira Garabato et al. (2004), who did not find an association between fronts and mixing rates. Our direct turbulent dissipation measurements were limited to the Austral Summer season, and therefore do not shed light on possible seasonal variability of mixing that has been reported by Thompson et al. (2007). Given that the strength of the near-bottom flow incident on bathymetric features appears to be the most critical indicator of mixing intensity via lee-wave processes, eddy variability of the ACC may dictate the temporal variability of mixing in the deep Southern Ocean rather than seasonal forcing.

Of primary interest to DIMES is the diapycnal mixing acting within the deep water masses. We focus here on the density surface targeted by the on-going tracer release experiment (Ledwell et al. 2011; A. Watson et al. 2012, unpublished manuscript). This surface, the $\gamma_{n}=$ $27.9 \mathrm{~kg} \mathrm{~m}^{-3}$ neutral density contour, varies in depth from 600 to $2000 \mathrm{~m}$ (south to north) across Drake Passage with a mean depth of $\sim 1500 \mathrm{~m}$ (as shown in Figs. 4 and 5). Diapycnal diffusivities were calculated using an ensemble over a depth interval $\pm 250 \mathrm{~m}$ about the tracer density surface for each profile. Along the ALBATROSS section, we find $k_{\rho}=(2.1 \pm 0.4) \times$ $10^{-5} \mathrm{~m}^{2} \mathrm{~s}^{-1}$ characterizes the mean and $95 \%$ confidence limits for the diffusivity about the tracer density surface. In contrast, along the Phoenix Ridge the mean diffusivity about the tracer surface is $k_{\rho}=(1.3 \pm$ $0.15) \times 10^{-4} \mathrm{~m}^{2} \mathrm{~s}^{-1}$.

We compare our results to the preliminary findings of A Watson et al. (2012, unpublished manuscript) from the tracer experiment. West of Drake Passage, they find a diapycnal diffusivity of $1.3-2.5 \times 10^{-5} \mathrm{~m}^{2} \mathrm{~s}^{-1}$ averaged from the point of release at $105^{\circ} \mathrm{W}$ to the ALBATROSS section, which is consistent with our result there. Tracer analysis for Drake Passage (from the ALBATROSS section to $58^{\circ} \mathrm{W}$ ) is ongoing, but preliminary results suggests a diapycnal diffusivity of $O\left(10^{-4}\right) \mathrm{m}^{2} \mathrm{~s}^{-1}$, similar to our Phoenix Ridge observations. However, the relevance of this comparison is unclear, as the microstructure estimates represent snapshots of the dissipation rate levels on specific sections, while the tracer result represents an average of the mixing processes acting on the tracer field over a vast spatial area.
We have considerable interest in understanding how the turbulence levels observed at the Phoenix Ridge compare with turbulence levels further downstream. That our Phoenix Ridge diffusivity estimate is comparable with that deduced from the tracer in Drake Passage suggests that our turbulence measurements succeeded in characterizing a useful mean estimate. To the extent that the turbulence levels are the result of lee waves, and that lee waves typify the downstream internal wave environment, it is likely that turbulence levels comparable to those we observed at the Phoenix Ridge are acting on the tracer over a broad area. Indeed, the $O\left(10^{-3}\right) \mathrm{m}^{2} \mathrm{~s}^{-1}$ diffusivities inferred by Thompson et al. (2007) from Thorpe scales and CTD strain in the upper $1000 \mathrm{~m}$ of the water column were for a site roughly $150-\mathrm{km}$ downstream of the Phoenix Ridge. How such large mixing rates are sustained that far downstream of the Phoenix Ridge, and that shallow, is an unresolved issue, but one of primary interest to potential future work.

Acknowledgments. We thank the crews and technicians on the R/V Thomas G. Thompson and the RRS James Cook. Invaluable assistance with the work was provided by A. Bogdanoff, P. Courtois, K. Decoteau, R. Krishfield, S. Lambert, K. Sheen, and others. R. Ferrari, E. Kunze, and M. Nikurashin provided valuable comments on the draft material for the manuscript. This work was supported by the U.S. National Science Foundation and by the Natural Environment Research Council of the United Kingdom.

\section{REFERENCES}

Dillon, T. M., 1982: Vertical overturns: A comparison of Thorpe and Ozmidov scales. J. Geophys. Res., 87 (C12), 96019613.

Ferron, B., H. Mercier, K. Speer, A. Gargett, and K. Polzin, 1998: Mixing in the Romanche fracture zone.J. Phys. Oceanogr., 28, 1929-1945.

Gregg, M. C., 1999: Uncertainties and limitations in measuring $\varepsilon$ and $\chi . J$. Atmos. Oceanic Technol., 16, 1483-1490.

Heywood, K. J., A. C. Naveira Garabato, and D. P. Stevens, 2002: High mixing rates in the abyssal Southern Ocean. Nature, 415, 1011-1014.

Klymak, J. M., and Coauthors, 2006: An estimate of tidal energy lost to turbulence at the Hawaiian Ridge. J. Phys. Oceanogr., 36, 1148-1164

Kunze, E., E. Firing, J. Hummon, T. Chereskin, and A. M. Thurnherr, 2006: Global abyssal mixing inferred from lowered ADCP shear and CTD strain profiles. J. Phys. Oceanogr., 36, 15531576.

Ledwell, J. R., A. J. Watson, and C. S. Law, 1993: Evidence for slow mixing across the pycnocline from an open-ocean tracerrelease experiment. Nature, 364, 701-703. 
, E. T. Montgomery, K. L. Polzin, L. C. St. Laurent, R. W. Schmitt, and J. M. Toole, 2000: Evidence for enhanced mixing over rough topography in the abyssal ocean. Nature, 403, 179-182.

— L. C. St. Laurent, J. B. Girton, and J. M. Toole, 2011: Diapycnal mixing in the Antarctic Circumpolar Current. J. Phys. Oceanogr., 41, 241-246.

Lumpkin, R., and K. Speer, 2007: Global ocean meridional overturning. J. Phys. Oceanogr., 37, 2550-2562.

MacKinnon, J. A., and K. B. Winters, 2005: Subtropical catastrophe: Significant loss of low-mode tidal energy at 28.9 degrees. Geophys. Res. Lett., 32, L15605, doi:10.1029/2005GL023376.

Munk, W., 1981: Internal waves and small-scale processes. Evolution of Physical Oceanography, B. A. Warren and C. Wunsch, Eds., The MIT Press, 264-291.

Naveira Garabato, A. C., K. L. Polzin, B. A. King, K. J. Heywood, and M. Visbeck, 2004: Widespread intense turbulent mixing in the Southern Ocean. Science, 303, 210-213.

— D. P. Stevens, A. J. Watson, and W. Roether, 2007: Shortcircuiting of the overturning circulation in the Antarctic Circumpolar Current. Science, 447, 194-197.

Nikurashin, M., and R. Ferrari, 2010: Radiation and dissipation of internal waves generated by geostrophic motions impinging on small-scale topography: Application to the Southern Ocean. J. Phys. Oceanogr., 40, 2025-2042.

Osborn, T. R., 1980: Estimates of the local rate of vertical diffusion from dissipation measurements. J. Phys. Oceanogr., 10, 83-89.

Polzin, K. L., 2004: Idealized solutions for the energy balance of the finescale internal wave field. J. Phys. Oceanogr., 34, 231-246.

-, J. M. Toole, J. R. Ledwell, and R. W. Schmitt, 1997: Spatial variability of turbulent mixing in the abyssal ocean. Science, 276, 93-96.
E. Kunze, J. Hummon, and E. Firing, 2002: The finescale response of lowered ADCP velocity profiles. J. Atmos. Oceanic Technol., 19, 205-224.

Rudnick, D. L., T. J. Boyd, R. E. Brainard, and Coauthors, 2003: From tides to mixing along the Hawaiian Ridge. Science, 301, 355-357.

Schmitt, R. W., J. M. Toole, R. L. Koehler, E. C. Mellinger, and K. W. Doherty, 1988: The development of a fine- and microstructure profiler. J. Atmos. Oceanic Technol., 5, 484500 .

Sloyan, B., 2005: Spatial variability of mixing in the Southern Ocean. Geophys. Res. Lett., 32, L18603, doi:10.1029/2005GL023568.

Smith, W. H. F., and D. T. Sandwell, 1997: Global sea floor topography from satellite altimetry and ship depth soundings. Science, 277, 1956-1962.

St. Laurent, L., and R. W. Schmitt, 1999: The contribution of salt fingers to vertical mixing in the North Atlantic Tracer Release Experiment. J. Phys. Oceanogr., 29, 1404-1424.

— , and C. Garrett, 2002: The role of internal tides in mixing the deep ocean. J. Phys. Oceanogr., 32, 2882-2899.

_ , and H. Simmons, 2006: Estimates of power consumed by mixing in the ocean interior. J. Climate, 19, 4877-4890.

Thompson, A. F., S. T. Gille, J. A. MacKinnon, and J. Sprintall, 2007: Spatial and temporal patterns of small-scale mixing in Drake Passage. J. Phys. Oceanogr., 37, 572-592.

Thurnherr, A. M., L. St. Laurent, K. G. Speer, J. M. Toole, and J. R. Ledwell, 2005: Mixing associated with sills in a canyon on the midocean ridge flank. J. Phys. Oceanogr., 35, 13701381.

Zika, J. D., B. M. Sloyan, and T. J. McDougall, 2009: Diagnosing the Southern Ocean overturning from tracer fields. J. Phys. Oceanogr., 39, 2926-2940. 